\title{
Organizational Effectiveness of Training Prospective Specialists in Student Extracurricular Activitiesat the University Level
}

\author{
S.Tazhbayeva \\ M.Assilkhanova \\ L.Ilimkhanova \\ aPhD of Pedagogy, Abay Kazakh National Pedagogical University \\ ${ }^{b} P h D$ of Pedagogy, Abay Kazakh National Pedagogical University \\ Independent Researcher of Social Sciences \\ lyazzat.ilimkhanova@gmail.com
}

Doi:10.5901/mjss.2014.v5n20p2608

\begin{abstract}
This article examines theorganizational effectivenessoftraining prospective specialists in student extracurricular activitiesat the university level by first evaluating the competence of penultimate-year students and then comparing theirinitial competence level to the moral and volitional perspectives of prospective specialists in extracurricular activities.After the summarized data was compared with the survey results, the findings indicate that when utilizing student competence as the main criteria, it effectively presented an ideal model of a specialist in extracurricular activities at the university level.
\end{abstract}

Keywords: studentpersonality formation, studentextracurricular activities, student competence, moral and volitional sphere of personality

\section{Introduction}

Changes that occur in all spheres of social life have a significant effect onthe relationshipsbetweensociety and individuals. Over time, these relationships become more stringent, thus requiring a higher degree of competitiveness fromall the participants. Conversely, because of the need to resolve certain social issues, such associations have inspired self-determination and self-realization,as well as new approaches oforganizing activities inintegral pedagogical processesthroughboth traditional and nontraditional methods. Currently,there is a need for moreinnovativeresearch, not only regarding the organization of the educational process but also regarding the structure of relations between professors and students. Therefore, with fullcooperation and equal partnership between these two parties, this study examines the organizational effectiveness of training prospective specialists in student extracurricular activities at the university level.

\section{Materials and Methods}

The professor, as an effective organizer and specialist instudent extracurricular activities, helps each student discover and fulfill their need forknowledge and introduces aspects regarding modern culture. Based on this perspective, it is important to note that the professor is responsible for organizing the activities and predicting the outcomes, while the student is responsible only for his/her own behavior duringthe activity. In other words, the educational process is always a purposeful process in which the teacher establishes certain goals and the student can only become the participant in the activity.

The overall goalfor professors is to effectively and consciously guide students in theirdevelopmental processes. Teamwork, organized by theteacher, is a syncretic unity of the social value of the students' life objects, the social values of the individual transformed into the students' personality meaning, and thefunctions that bring him/herto interact with reality.The pedagogical value of group work is determined by the active involvement of each group member and the transfer of knowledge through organized activities. In addition, personality is the primary value in group work, and for each member to receive a high level of self-satisfaction this aspect must be recognized. All of these aforementioned assumptions form the basis for this analysis and help formulate the moral and volitional perspectiveof prospective 
specialists in extracurricular activities(Tazhbayeva\&Syzdykbayeva, 2005).

\section{Results}

Effective pedagogical systems that educate and prepare future specialists in extracurricular activities must include continuous evaluation to achieve the highest outcomes. Therefore, this study compared the initial state of preparedness of pre-graduate students to the moral and volitional perspectiveof prospective specialists in extracurricular activities. Theassessment was performed in three overall stages: the first stage (2005-2007), the second stage (2007-2009), and the third stage (2009-2012), which were based on actual materials utilized by teachers and students from various universities.

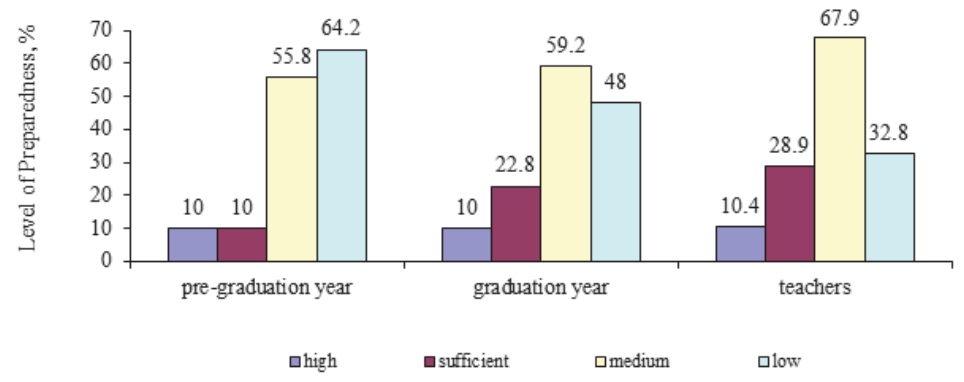

Figure 1 - Preparedness level for formulating an identity as a specialist in extracurricular activities

According to Figure 1 , only $10 \%$ of students and $10.4 \%$ of teachers had a high preparednesslevel for formulating an identity as a specialist in extracurricular activities. It is important to note that there were some graduates who hadpreviously completed specific training on establishingan identity as a specialistin extracurricular activities. Since students cannot naturally achieve a high preparednesslevel withoutrepeated contact, we conducted the first and second pedagogical practices over a four-month period. However, for students in the experimental groups, this time period proved to be insufficient for achieving optimal results (Tazhbayeva, 2005).

A comparison of thepreparednesslevel of students in the experimental groups and teachers indicates that they wereapproximately at the same level; the difference in thesufficient level is $6.1 \%$ with an average of 8.7\%. Thecomparative data indicates that students are not specially trained to formulate an identity as a specialist in extracurricular activities.In this case, approximately one in five teachers will have a sufficient preparednesslevel.

Finally, we consider how specific courses such as "Activity of Class Teacher in Moral Education of Pupils," and educational textbooks including the "Education of a Future Teacher" and "Preparation of a Future Teacher forMoral Education of Pupils" enhances the preparednesslevel for prospective specialists in extracurricular activities.To examine the basic criteria and indicators of preparedness, we have developed methods of diagnosis by utilizingappropriate psychological and pedagogical toolsets. Figure 2 summarizes the preparedness level based on the results of the experimental work (Tazhbayeva, 2005).

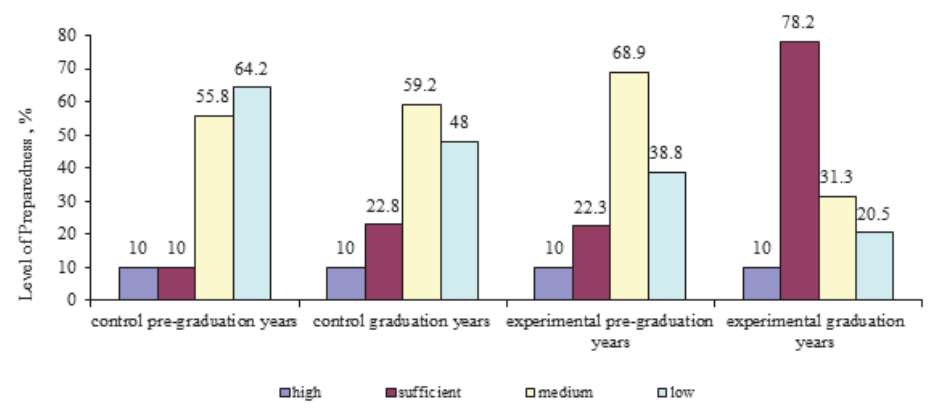

Figure 2 - Preparedness level of students for formulating an identityasa specialist in extracurricular activities 
According to Figure 2, 38.8\% of the experimental pre-graduation group had a low preparednesslevel,while the control pre-graduation groups in the same year was $64.2 \%$.Meanwhile, the preparedness level for the control graduation group was $48.0 \%$,while the experimental graduation groupwas only $20.5 \%$.A comparison of the students in the pre-graduation and graduation groups (experimental and control) groups indicate that $22.3 \%$ of students in experimental pre-graduation group had a sufficient level of preparedness. Finally, $78.2 \%$ of students in theexperimental graduation group hada sufficient preparednesslevel,whileboth control groups in the same year were only $10 \%$ and $22.8 \%$ of students, respectively.

\section{Discussion}

Since both control groupsindicated a slight increase in their preparednesslevels, how can we explain this increase? Based on our observations, the students in thecontrol groups indicateda natural increase in their preparedness level through acquisition of practical and pedagogical experiences in school, which suggests that students require such practice to formulate an identity as a specialist in extracurricular activities.For a more objective evaluation of the results obtained from the student surveys, we compared the results of the analysis to the preparednesslevel of teachers in different regions of the Republic of Kazakhstan. It should be noted that, except for the master teachers, the vast majority of teachers cannot independently formulate moral and volitional perspectives for prospective specialists in extracurricular activities. This findingis confirmed by the results of the practical activities in both thecontrol groups.

After comparing students in the experimental group and schools, we obtained completely different results. For example, graduate students with a preparedness levelof $39.3 \%$ were approximately twicemore than teachers and fivetimes more than the students in the control group. This finding indicates that thetraining of prospectiveteachers effectively contributes toward a significant increase in a sufficient of preparedness. With regard to the students in the experimental group, there was a $39.3 \%$ increase in the preparednesslevel. Such growth was due to the reduction of indicators in themedium and low preparednesslevels. Similar changes occurred in the analysis of the students in experimental pre-graduation group in which $22.3 \%$ of the students had an adequate preparednesslevel, which was $6.1 \%$ more than the teachers. These results again confirm our conclusion of the reasonability and necessity for a more focused preparation of prospective specialists in student extracurricular activities (Tazhbayeva, 2007).

The analysis of the students in control pre-graduation graduation groups suggests that unless there is special instruction,the preparedness of students will be remain at low and medium levels. Unless significant changes are made, future students will experience similar difficulties when formulating an identity as a specialist in student extracurricular activities.

A study on the vocational and educational activities of future teachers was conducted by C. Zamfir (under A. A. Rean)based on the concept of internal and external motivation. Table 1 presents the scale of professional activity motives. If motivation of professional activity is based on the aspiration and satisfaction of needs that are external to the content of the activity,such as motives of social prestige, salaries, then it is external motivation. External motives are divided intoexternal positive (EPM) and external negative motives (ENM) (Tazhbayeva, 2007).

Table 1 - Scale ofprofessional activity motives

\begin{tabular}{|c|c|c|c|c|c|c|}
\hline № & Professional activity motives & 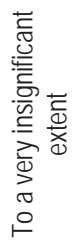 & 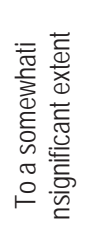 & 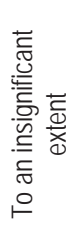 & 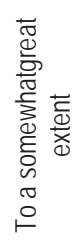 & 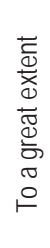 \\
\hline 1 & Cash earnings & 4 & 3 & 2 & 1 & 1 \\
\hline 2 & Jobpromotions & 3 & 3 & 2 & 1 & 1 \\
\hline 3 & Avoiding criticism from managers or colleagues & 3 & 3 & 2 & 2 & 1 \\
\hline 4 & Avoiding penalties or hassles & 3 & 3 & 3 & 2 & 1 \\
\hline 5 & Earning social prestige and respect from others & 1 & 2 & 3 & 4 & 4 \\
\hline 6 & Work satisfaction & 1 & 3 & 4 & 4 & 2 \\
\hline 7 & Opportunity for self-realization in this particular activity & 1 & 2 & 5 & 4 & 3 \\
\hline
\end{tabular}


Data regarding work satisfaction includes a significant correlation with the optimalmotivational complex of a teacher (positive significant correlation $\mathrm{g}+0.424$ ). In other words,the higher theoptimal motivational complex of a teacher, the higher his/her satisfaction. The self-assessment of professional fitness and abilities of students in teaching plays animportant rolein determining the effectiveness of formulating an identity as a specialist in student extracurricular activities.

Withregard to self-assessment of professional fitness and abilities, there are a number of attributes that characterize the positive aspects of the ideal teacher. Figure 3presents the results of a self-assessment survey regarding the professional fitness and abilities of graduates in teaching activities.

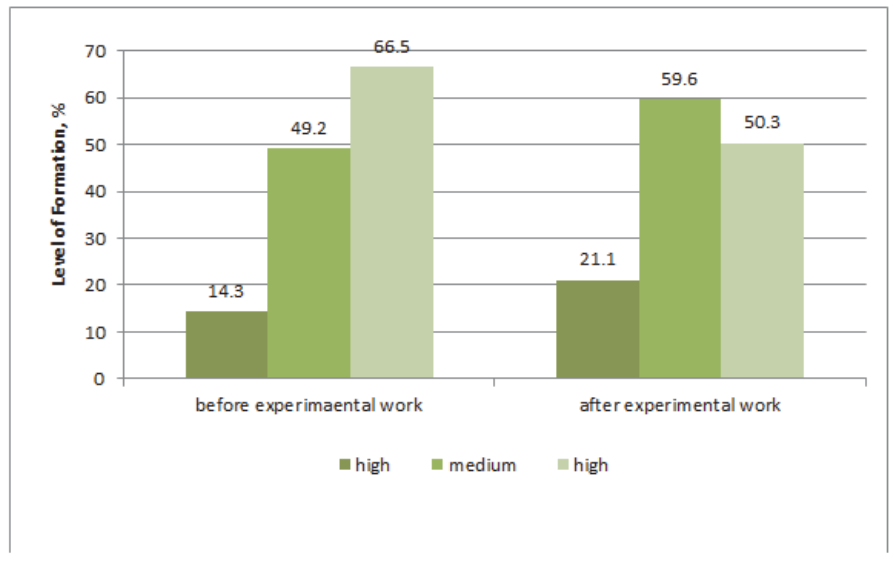

Figure 3 - Self-assessment survey results regarding the professional fitness and abilities of graduate students in teachingactivities

According to Figure 3, there was a high formation level (21.1\%) characterized by high self-esteemthat wassustainable. In this case, future teachers know quite well what qualities they have developed, and thus, they have a sufficient selfeducationlevel.The average formation level of students (59.6\%) after the experimental work is characterized by the fact that self-esteem was intermediate between the high and low levels. In addition, the low formation level (50.3\%), characterized by low and contradictory self-esteem, indicated that these students included no aspiration to improve.

Ananalysis of the practical activitiesof students inthe experimental groupindicates that we were not dealing with thechange of teaching style nor the educational situation. Furthermore, the search for such techniques and technologies that promote maximum individual insight can have a positive effect on consciousness, self-detection, the formation of moral and volitional qualities, and responsibility of each student for their actions and behaviors.

Central to the entire process is the ability to communicate with students, initiate their energy, and stimulate the maximum individual expression during the moment of creativity. For example, we conducted educational work with students in the Physics and Mathematics Faculty at the Kazakh State Female Pedagogical Institute and modernized their extracurricular activities by holding competitive games such as "What? Where? When?"as well as a physical and mathematical analogy of the game,"Name That Tune." In addition, we organized educational and interactive activities that taught students and parents abouthealthy lifestyles. The scripts of the activities are provided in the appendix (Tazhbayeva, 2008).

Working with our proposed methods and the wide array of methodological developments and scenarios, teachers can transform their general educational approach and professional attitudes and adapt them to new educational conceptsthat help formulate moral and volitional personalities.

\section{Conclusion}

This article examined theorganizational effectiveness of training prospective specialists in student extracurricular activities at the university level. The findings indicated that such preparation should be conducted during their learning not only within thesystem of educational extracurricular activities with the students but also through special courses such as "The Theory of Education and Educational Technology at the University" and "Fundamentals of Pedagogical Skills," as well as 
pertinent educational textbooks and learning aids.In addition, the necessity to focus onthe moral and ethical qualities ofprospective teachers was confirmed during the experimental work with two participating groups (experimental and control)atvarious schools. The results also confirm that the higher the preparedness level of theteacher, the more fully realized the student becomes both asan individual and as a specialist in extracurricular activities.

We are aware of the fact that the quality and effectivenessof our methods is limited because we focused on a certain group of students and that the overall experiment was conducted within a short time period. However, this study indicated that utilizingour programs and methodological recommendations enhanced theorganizational effectiveness of training prospective specialists in student extracurricular activities at the university level.

\section{References}

Tazhbayeva, S.G., \&Syzdykbayeva, G.Y. (2005). The analysis of preparedness level of professional competence of perspective teachers in extracurricular activities in higher education. International scientific practical conference journal (Almaty, Kazakhstan): "History and modern tendencies of the development of the Republic of Kazakhstan," 168-171.

Tazhbayeva, S.G. (2005). The analysis of preparedness level of perspective teachers in extracurricular activities in higher education. Third international scientific conference journal (Kaliningrad, Russia): "Europe and modern Russia," 25-28.

Tazhbayeva, S.G. (2005). The analysis of the results of conducted research on preparation of perspective teachers in extracurricular activities in higher education. Third international scientific conference journal (Warsaw, Poland): "Integrated function of pedagogical science in international educational world," 17-21.

Tazhbayeva, S.G. (2005). The diagnostics of organizational process in extracurricular activities in higher education. "Kainar" university journal, 2 (2), 62-67.

Tazhbayeva, S.G. (2007). Tendencies in the spiritual and moral development of young students. Thirteenth international scientific conference journal (Sarajevo, Bulgaria): "Comparativeeducationsocieties," 219-224.

Tazhbayeva, S.G. (2007). The effectiveness of the work conducted on preparation of perspective teachers in extracurricular activities in higher education. International scientific practical conference journal (Almaty, Kazakhstan): "Preschool and primary education: current state, tendencies and issues of development," 647-655.

Tazhbayeva, S.G. (2008). Organization of extracurricular activities of students. International scientific practical conference journal (Almaty, Kazakhstan): "Problems of the perspective of innovative technologies for preparation of teaching stuff quality upgrade," 551-554. 